\title{
Natural Entomophages of Brevicoryne Brassicae (L.) (Hemiptera: Aphididae) in Uzbekistan
}

\author{
Kahramon B. Razzakov ${ }^{1}$, Ikram. I. Abdullaev ${ }^{2}$, Ko'pal O. Saparboev ${ }^{1} \&$ Mavluda M. Allaberganova $^{1}$ \\ ${ }^{1}$ Urgench State University (UrSU), Urgench, Uzbekistan \\ ${ }^{2}$ Khorezm Academy of Mamun, Khiva, Uzbekistan \\ Correspondence: Kahramon B. Razzakov, PhD student Urgench State University, 220100, Urgench, Uzbekistan. \\ Tel: 998-362-224-6644. E-mail: q.razzoqov@mail.ru
}

Received: July 15, 2019

Accepted: July 31, 2019

Online Published: August 9, 2019

doi:10.5539/ijb.v11n4p42

URL: https://doi.org/10.5539/ijb.v11n4p42

\begin{abstract}
In our studies phenological phases of cabbage aphids Brevicoryne brassicae (L.) were studied. The influence of external factors (humidity and temperature) was studied under laboratory conditions. The maximum reproductive ability of cabbage aphids was noted in spring and autumn. Some of the parthenogenetic aphids gave about 82 larvae. The daily reproductive ability of aphids was $3-5$, and the maximum 5-11. When studying the reproductive ability of parthenogenetic aphids, this indicator was slightly lower than that of the wingless aphids (average 28, maximum 51). The overall development of cabbage aphid seeds averaged 7-9 days in summer and 12-21 days in early spring and autumn. The importance and bioecological features of Metamorphus corollae (F.), Episyrphus balteatus (De Geer, 1776), Syrphus vitripennis (Meigen, 1822), Scaeva pyrastri (L.) Coccinella septempunctata (L.) and Adonia variegata (G.), Chrysopa carnea Steph. with natural control of the cabbage aphid were studied.

Studying the biological effectiveness of a simple golden-eyed fly in relation to the cabbage bug, efficiencies were observed at a ratio of II-year-old larvae of simple golden-eyed and cabbage bug in a ratio of 1:5 and 1:10. For 4 day old gold-eyed eggs, this efficiency was observed when the ratio with cabbage bug was 1:1 on the 17th day of the experiment.
\end{abstract}

Keywords: Berlese, Oligophagous, Exhauster, Entomophagous, Insektarium

\section{Introduction}

Cabbage bug B. brassicae (L.) is a dispersed species of pest, and is found in every continent where cruciferous is grown, including cabbage. The diamondback moth (DBM), Plutella xylostella (L.) (Lepidoptera: Plutellidae), is ranked as the most destructive pest of brassicas throughout the world (Talekar \& Shelton, 1993; Sarfraz et al., 2005). In Zimbabwe, large scale and smallholder farmers grow brassicas as one of their principal crops and DBM is a major pest of cabbage Brassica oleracea var. capitata, covo Brassica oleracea var. acephala (Brassicales: Brassicaceae) and rape Brassica napus (L.) (Brassicales: Brassicaceae) (Jackson, 1997; Sibanda et al., 2000). Larsen (1974) recorded this species as feeding on Capparis in Lebanon. Records of Apple tree home Malus domestica Borkh, (Angiospermae: Rosaceae), pea Pisum sativum (L), (Fabales: Fabaceae) and aubergine Solanum melongena (L.) (Solanales: Solanaceae) are very doubtful. Pieris brassicae (L.) (Lepidoptera: Pieridae) is an oligophagous insect that feeds on members of family Brassicaceae (Lal \& Ram, 2004; Younas et al., 2004; Hwang et al., 2008; Hasan \& Ansari, 2010).

Observations are presented on the incidence, host plants, biology and parasitoids of Pieris brassicae in the western Cape region of South Africa since this pierid was first reported there in about July 1994 (Claasens, 1995). Damage to cabbage heads has been reported to be as high as 70-98\% (Prasad, 1962, 1963; Hasan \& Ansari, 2011) reported P. brassicae to be one of the most destructive and cosmopolitan pests of cruciferous crops in India, where it causes $40 \%$ of the damage to cruciferous crops per year. In Himachal Pradesh, India, P. Brassicae completes three generations in a year, the duration of which vary from 32-64 days. The first two generations during February-May inflict severe damage to cabbage and cauliflower. High temperatures and more sunshine hours, accompanied by low relative humidity and rainfall, favour population build-ups (Sood \& Bhalla, 1996). Under conditions of eastern Fergana, the cabbage moth was separated as a specific pest (Tursunkhodjaev, 1974). 
White cabbage is one of the leading vegetable crops in Uzbekistan. In vegetable farms of the Khorezm region, it occupies from 12 to $23 \%$ of the area. A system for protecting cabbage from a pest complex developed fragmentary. Virtually all studies are confined to specific climatic regions, against any single pest, the effectiveness of biological and chemical control agents, the regulations for their use and the environmental consequences are valid for limited territory. This determines the relevance of the presented studies to clarify the species composition and species structure of cabbage pests and different types of chemical composition and mechanism of action aimed at testing the set of protection of white cabbage from the pest complex in the Khorezm region. One of the factors restraining the growth of crop yields in the region and meeting the population's need for this product is that cabbage is damaged by pests annually throughout the growing season, in the same time, the species composition of phytophages has not been studied.

The tasks of the research: Refine the species composition and species structure of cabbage pests, To clarify the species composition of entomophagous pests of cabbage. Our data will be helpful for the better understanding to predict the number of major pests of cabbage, in planning and timely implementation of protective measures to combat them, which will optimize the use of chemicals in the cabbage agrocenosis fields and get ecologically clean products in future.

\section{Materials and Methods}

Field experiments were carried out on vegetable farms in the Kushkupir district of the Khorezm region (Uzbekistan) in the period from 2016-2018 and the collection of insects was carried out on the basis of generally accepted methods (Adashkevich, 1983; Fasulati, 1971; Khamraev, 1995, 2008). In the process of insect suppression, the traditional method was carried out by using entomological net and insect trap. An entomological net and insect trap was used to collect and record entomophages of cabbage pests (Figure 1 and Figure 2).

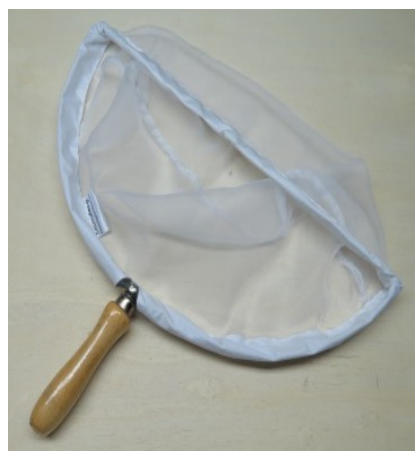

Figure 1. Entomological net

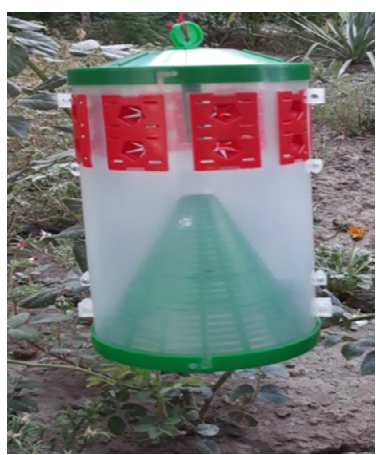

Figure 2. Insect trap

As a result of the research, more than 400 specimens of various insects were collected. The collected biomaterial was studied out in the laboratory conditions of the Khorezm Academy of Mamun and Urgench State University, systematics were carried out, and entomophages of some pests were grown from the pre-premagial development stage to an adult individual. To determine, study and obtain the larvae of all insects on the upper layer of the soil the Berlese apparatus was used, as described by Wetzel (1963). The apparatus was consisted of a laboratory lamp, a plastic funnel and a collecting vessel. A small lamp with a low-power light bulb (10-40 Watts) heated and dried the soil from above. As the soil dried out from the top down, the dryness stimulated the soil animals to move downward. This downward movement eventually caused the soil animals to fall through the sieve into a container with a preservative. All larval and adult Coleoptera were preserved in absolute ethanol (Figure 3). In addition, entomophages were collected from plants using an exhauster and, depending on the species, were kept in a laboratory in mounts and fed on plant food (Figure 4).

Recommended methods (Kopville, 1961; Suitmen, 1964; Adashkevich, 1983) were used to study the entomophages of cabbage pests. To assess the impact of entomophages on the dynamics of the number of cabbage aphids in the observed plants, after the appearance of pests, pests were counted once a week in 100 plants (5 plants out of 20 samples). In the result of observations infected plants were determined, the total number of leaves and the number of leaves infected with cabbage aphid. The number of bugs in 20 plants was counted separately (one infected plant from each sample). To do this, from each infected leaf in the center of the colony with aphids, a pallet with an area of $1 \mathrm{~cm}^{2}$ was cut out using a special device and the samples were placed in a test tube for study in the laboratory. At each inventory, the number of eggs, larvae, pupae, and adult 
individuals of coccinellids, Syrphidae, gold-eyed flies, and other predators were determined separately and registered in the book. The larvae and pupae of predators were grown in the laboratory until the appearance of an adult individual, and then the species composition of entomophages was determined.

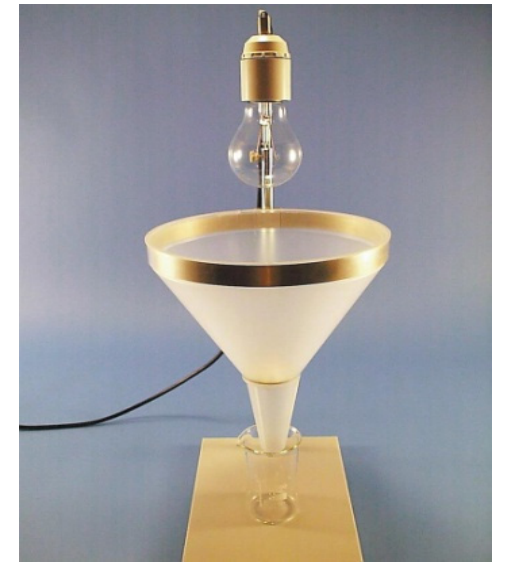

Figure 3. Berlese-Tullgren extractor

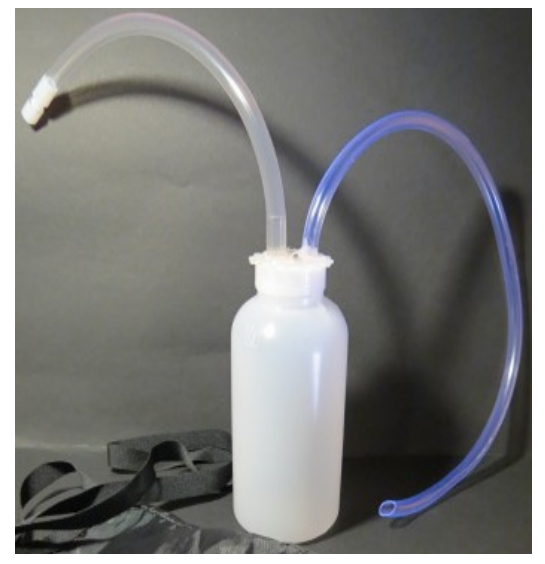

Figure 4. Exhauster

For this purpose, cabbage sprouts were grown in 20 pots and one adult was placed on each plant, the number of new larvae was counted every day, and one adult female was separated from each leaf with a brush, the number of larvae was registered in the book. Under the conditions of the experiment, the temperature and relative humidity were measured 4 times during the day. Experiments were continued from April till the end of October.

To determine the species composition and the purpose of such parasites as the cabbage white and diamondback moth, samples of whitefishes were collected 3 times from each generation in the range of 7-10 days. The larvae and pupae of the cabbage moth were collected from each generation 2 times: during the developmental period of the larva at 3 years of age and when becoming the pest into a pupa, observations were made on the dynamics of numbers and phenology. To determine the degree of pest infestation from 20 field locations (staggered), there were collected 5 samples total 100 samples of eggs, larvae and pupae of the pest and 50 samples of pest.

The biological efficiency of a simple golden-eyed was studied in laboratory and field conditions. The experiments were conducted in insektarium. For this, cabbage seedlings were grown in pots in the early spring and artificially infected with a cabbage bug. After settling cabbage bugs and reaching the number of bugs in each plant from 50 to 150 , the larvae or eggs of a simple golden-eye were planted on the plant in a fixed ratio. At the same time, to reduce the incubation period, the golden-eyed eggs were kept at $20-25^{\circ} \mathrm{C}$ for 4 days. The larvae in each pot were kept individually (Figure 5).

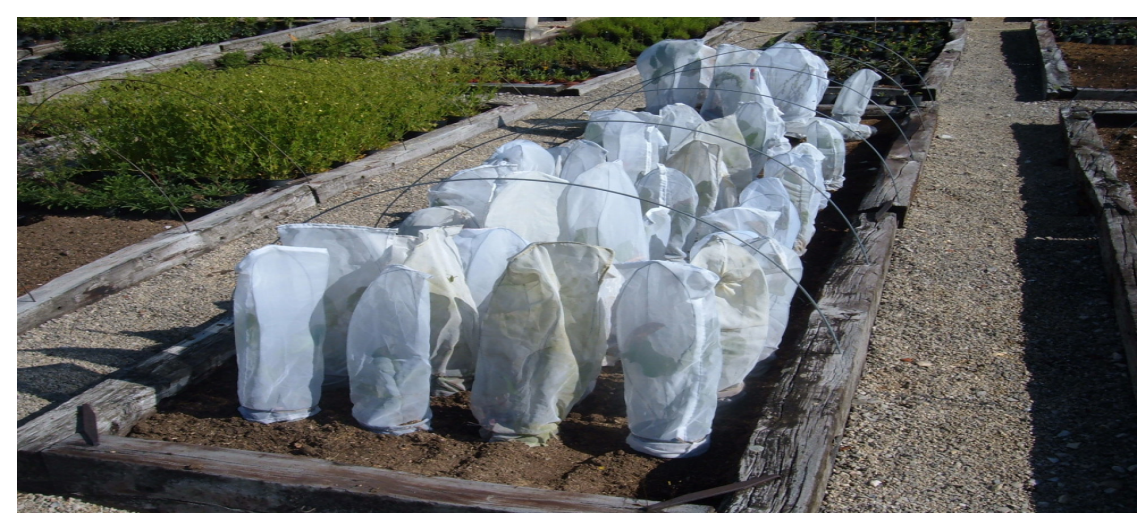

Figure 5. Insektarium 
In 2017, the different stages of the predator: eggs, I-and II-year-old larvae in relation to the bugs 1:15, 1:25 and 1:50 were investigated against cabbage bugs. In 2018, studies were conducted using 50 or 100 cabbage bugs and II-year old simple golden-eyed larvae in a ratio of 1:5, 1:10, 1:25, 1:50, and 4 day old eggs of a golden-eyed egg in a ratio of 1:1, 1:5. In the control in the pots of infected cabbage with the cabbage bug of the golden-eyed was not used. The experiments were conducted in four replications. The effectiveness of the experiments was determined on 5-8, 13-17 days after the end of feeding the larvae. The results of the research were statistically analyzed by using Biostat 3.8 programm.

\section{Results and Discussion}

In the study of bioecological features and predators of B. brassicae, autumn studies have determined the wintering phase of bedbugs on plant remains. Studies have shown that bugs hibernate in the remains of the cabbage crop and in other weed crucifers in the phase of eggs, larvae and adult insects.

And in special studies conducted in early spring, viviparous adult females, larvae of all ages and eggs of cabbage bugs were recorded. The larvae of hibernating eggs appeared in early April. With an increase in air temperature, propagation of bugs increases revealed. In the third weeks of April, large clusters of cabbage bugs are formed, they begin to harm early cabbage.

Although the results were differed slightly by months, the average fecundity of each cabbage aphid was 39 larvae. Under the conditions of the experiment, the air temperature ranged from 12 to $27^{\circ} \mathrm{C}$, the maximum temperature was $35^{\circ} \mathrm{C}$, and the relative humidity was $32-65 \%$. If we consider the fecundity of cabbage aphid, then the maximum fecundity occurs in the spring (April) and autumn (September, October) months. However, some parthenogenetic aphids were laid up to 82 pieces of larvae. The daily fecundity of aphids averaged 3-5, maximum was 5-11. In laboratory conditions, wingless females lived from 14 to 43 days.

When studying the fertility of winged parthenogenetic females, their indicators were less than the wingless females (on average 28, maximum 51). In cabbage aphids live birth continues until the end of life. In this case, it is possible to stop in a few days, after which the birth continues. Such days can be continued 2-6 days, in some cases for 6-10 days. In the experiments, $32-35 \%$ of the aphids died tomorrow after the cessation of birth. In experiments, some aphids continued additional feeding after cessation of birth. On average, such additional feeding lasted 3-5 days, maximum was 10 days. The overall development of one generation of cabbage aphids on average during the summer months was 7-9 days, in spring and autumn was 12-21 days.

Many researchers who had been working with cabbage pests especially emphasized the role of natural entomophages in reducing the number of cabbage phytophages (Yarkulov, 1997). In the territories of former Soviet republics especially in Baltic states, Belorussia, Ukraine amd Moldova (Adashkevich, 1971), Transcaucasia (Akhmedov, 1977; Safaryan, 1968), Russian Federation (Osmolovskiy, 1972), Central Asia (Adashkevich, 1989; Daminova, 1989; Pashenko, 1965) was carried out an extensive research on study the entomophages of cabbage aphid.

There was given the data of scientists on the importance of aphidophages in reducing the number of cabbage aphids (Pimental, 1961; Broussol et al., 1961; Hafez, 1961; Stary, 1970). In reducing the number of cabbage aphids lacewing parasitoids are of particular importance [Hymonoptera]. Among them, the family of ichneumon flies is 55-92\%. In reducing the pests predators are less important (Adashkevich, 1983, 1989). In reducing the number of cabbage, turnip and Chantal moth parasitoids and predators play an important role. In all territories where this pest is spread, Apanteles glomeratus (L.) and the parasite of the pupa Pteromalus puparum (L.) are considered as the main endoparasitoids. Apanteles (Hymenoptera: Braconidae) infects the initial four year old, especially one and two year old larvae of the whitefishes.

Up to 100 parasitoids larvae can develop simultaneously in one caterpillar. The fecundity of the female parasitoid is very high and amounts about 2000 eggs. Over the year, Apanteles develops, giving 2-5 generations (Osmolovskiy, 1964; Shapiro, 1970). The biology of Pteromalus was somehow studied (Maslennikova, 1968). Pteromalus puparum (L.) besides pupae of whitefishes cause the harm to papue of 15 species of butterflies. Young caterpillars of white fishes can be damaged by ichneumon flies. Coccinellids, bugs, gold-eyed flies, syrphidus, gallbane and levkopis flies pilfer at the expense of cabbage aphid.

\subsection{Syrphidae (Insect: Diptera)}

According to many researchers (Adashkevich, 1983; Daminova, 1986), sirfid flies are of particular importance in the natural management of the number of cabbage aphids. Since mosquito larvae do not have legs, their migration (movement) is limited. Therefore, they destroy cabbage aphids and clear the area around them from the pest. 
In the conditions of Uzbekistan, the syrphid flies winter in the larval phase, but in cold snowy winters they can winter in the pupal phase (Daminova, 1986). Found that the species Metasyrphus corollae (Fabricius, 1794), Episyrphus balteatus (De Geer, 1776), Syrphus vitripennis (Meigen, 1822), Scaeva pyrastri (L.) may winter in the phase of an adult mosquito. Syrphid flies winter on plant residues and in the soil. The transformation into a pupa occurs during wintering.

If in 2017 the flight of mosquitoes from wintering was observed at the end of February, then in 2016 and 2018, the flight was observed at the beginning of March. Their mass flight in 2017 was observed in the middle of March, and in 2016 and 2018 in the third decade of March. Sexually crossing of syphids happened in early April. Syrphidae lay lengthened white eggs in the areas of plant aphid, among the clusters of aphids separately. Their eggs can be observed in all plants where aphids develop. To determine the duration of larvae coming out from the syrphid fly eggs, laid among the aphids during the season, freshly laid eggs were selected and observed in the laboratory, and it was established that the larvae appear during the day. Seasonal observations show that the incubation period for eggs of syrphid fly is 2-5 days.

To determine the life time of the larvae in 10 mounts located in the center of the garden, the larvae were laid and every day the leaves infected with cabbage aphids were changed. At the bottom of the mounts was put the soil mixed with sand $5 \mathrm{~cm}$ thick to create the required moisture, the soil in the mounts was moistened every other day. In the mounts was observed eating the cabbage aphids by the syrphid flies during the day, and the aphids were especially intensely eaten during the cool hours of the day. In experiments the duration of development of the larvae was 7-15 days. The larvae that had completed development fell to the bottom of the mount and turned into pupae. To determine the duration of development of the pupae, the observation was continued. Adult flies flew on 6 th day of the observation. The last flight of an adult individual was on the $10^{\text {th }}$ day. Thus, for one complete cycle of development of the syrphid fly, it takes from 15 to 30 days. Mass reproduction of syrphid fly on cabbage was observed in May-June. In July and the first half of August, due to a sharp jump of the temperature, was observed a moderate decrease in the number of syrphid.

In September-October, when the temperature drops to $22-28^{\circ} \mathrm{C}$, the number of syrphid on late cabbage increases sharply and is 22-46 larvae on each cabbage. Adult individuals actively fly during daylight hours. But they are especially active in the morning (9-12) and in the evening (18-20) time. With sunset, their activity ceases and they are located on the lower storey of plants.

\subsection{Coccinellidae (Insect: Coleoptera)}

In cabbage fields, typical types of cabbage stations of coccinellidas or ladybugs and cabbage-eating species are recorded as: Coccinella septempunctata (L.); Coccinula quatuordecimpustulata (L.); Propylea quatuordecimpunctata (L.); Adonia variegate (Gz.); Scymnus rubromaculatus (Gz.) and Scymnus frontalis (Fabricius), during the whole season, larvae and beetles of the species C. septempunctata and Adonia variegate play a special role in reducing the number of cabbage aphids. Other species among cabbage aphids are rare.

It should also be noted that the distribution of coccinellids by station is a inherent feature to biota, they are consisted of typical and accidental species. An important feature of typical species is that they develop in this biotope and carry out the phase of the larva and adult insect in this environment. Accidental species are found in biotopes only in the phase of adult beetles, the larvae of these species are rarely found in these biotopes.

As an accidental species of agrocenosis cabbage, we registered: Coccinella undecimpunctata (L.); Hippodamia tredecimpunctata (L.); Adalia decempunctata (L.); Adalia bipunctata (L.); Syngarmonia conglobata (L.); Exochomus flavipes. During 2016-2017 2150 ladybugs were collected, including 930 Coccinella septempunctata (L.) (43.25\%), 670 Adonia variegate (31.16\%) and 550 other species (25.58). Thus, in the Khorezm oasis, the ratio between the species of ladybird beetles of cabbage agrocenosis of dominant species has not been established. However, it should be noted that during the year this ratio varies, and the number of $C$. septempunctata species increases to $47.9 \%$.

Changes in wintering types of $C$. septempunctata are the result of a high ecological adaptability of the species. This allows its widespread and adaptability to various circumstances. In addition, C. septempunctata often develops typical and group wintering properties. In general, in coccinellids are clearly expressed mass gatherings and flights to the wintering grounds. For example, such large migrations for wintering are characteristic of C. septempunctata species.

Flight of beetles after wintering is observed at the end of the second and the beginning of the third week of March, when the average daily temperature exceeds $10^{\circ} \mathrm{C}$. For example, in 2016, the first C. septempunctata beetles were observed in the fields on March 19, and in 2017 on March 23. Since during this period the plants did not have 
aphids, the beetles ate flowers, buds and small clusters of aphids, and with the appearance of the first clusters of cabbage aphid the beetles moved to these plants. By 2018, it happened on April 23. From the second half of the third decade of April (April 27) the ladybug began to lay eggs in the aphids. At the beginning of the early May, the ladybugs and its larvae began to feed on cabbage aphids simultaneously. In June, a sharp increase in the number of ladybirds was noted in the agrocenosis of cabbage. In the second half of this month (June) the number of beetles in one cabbage was 42-48.

\subsection{Chrysopidae (Insect: Neuroptera)}

Among entomophages of agricultural pests, golden-eyed lacewings are of great practical interest. Among the previously mentioned species Chrysopa carnea; Ch. formosa; Ch. dubitans; Ch. septempunctata in cabbage and other vegetables common golden-eyed lacewing $\mathrm{Ch}$. carnea is often and massively found. The common golden-eyed lacewing is an effective, natural fighter of plant aphids, arachnid bugs, and cotton budworm eggs. Adult individuals of this species winter in buildings, under the bark of trees. Ordinary golden-eyed lacewing after wintering occurs in nature, starting in April.

Adult insects fly at a later time and strive for night lighting. As a result of the research, the timeframe for the development of each stage of the common golden-eyed lacewing has been established. Studies have shown that the intensive development of golden-eyed lacewing depends directly on temperature and relative humidity. The development of the larvae occurs at $+23^{\circ} \mathrm{C},+25^{\circ} \mathrm{C}$ and $65-70 \%$ of relative humidity (Table 1 ).

Table 1. The effect of air temperature and relative humidity on fecundity in the development of ordinary golden-eyed lacewing $(\mathrm{M} \pm \mathrm{m}, \mathrm{n}=8)$

\begin{tabular}{lllllll}
\hline № & Temperature $\left({ }^{\circ} \mathrm{C}\right)$ & Humidity $(\%)$ & Duration of stay of adult insect & Larvae & Pupae & Fecundity \\
\hline \multirow{3}{*}{1} & \multirow{3}{*}{30} & 40 & 11 & $10,0 \pm 0,47$ & $6,0 \pm 0,32$ & $82,0 \pm 0,81$ \\
& 60 & 10 & $9,0 \pm 0,73$ & $8,0 \pm 0,54$ & $23,0 \pm 0,86$ \\
& & 80 & 12 & $9,0 \pm 0,65$ & $9,0 \pm 0,71$ & $75,0 \pm 0,34$ \\
\multirow{2}{*}{$20-30$} & 40 & 24 & $11,0 \pm 0,96$ & $16,0 \pm 0,83$ & $158,0 \pm 0,73$ \\
& \multirow{2}{*}{20} & 60 & 30 & $11,0 \pm 1,07$ & $13,0 \pm 0,71$ & $398,0 \pm 0,73$ \\
& & 80 & 9 & $12,0 \pm 1,24$ & $16,0 \pm 0,89$ & $50,0 \pm 0,64$ \\
\hline
\end{tabular}

Note: dependence of the development of larvae, pupae and fecundity on temperature and humidity, $\mathrm{P}<0,001$

When feeding of the larvae on cabbage aphids, the development of the stages was: first age 5-10 days, second 4-8, third 2-8 days before turning into a pupa; pupa development 9-14 days. When the larvae fed on melon aphids, these indicators were properly 4-9.3; 7.2; 7 and 8-12 days. Thus, for the complete development of the golden-eyed lacewing depending on the air temperature, when feeding on cabbage aphids takes $20-40$ days, and when feeding on melon aphids, it takes 17-35 days.

In the following experiments, the effect of different temperatures and relative humidity on the development of the ordinary golden-eyed lacewing was investigated. Therein, at a constant air temperature of $30^{\circ} \mathrm{C}$, the development of the larvae was 8-9 days, pupae - 4-6 and adults - 8-12 days; with a changeable temperature of $20-30^{\circ} \mathrm{C}$, the indicators were 9-10, 11-14 and 30 days, respectively. As can be seen from the abovesaid, temperatures affect the development of the common golden-eyed lacewing. At the same time, a temperature of $20-30^{\circ} \mathrm{C}$ and a relative humidity of $60 \%$ are the optimal condition for entomophagy. Under these conditions, the life duration of imago was 30 days, and the fecundity - 396 eggs. At the same time, the effectiveness of the ordinary golden-eyed lacewing under various density of occupation with cabbage aphids in the field and laboratory conditions was studied. Preliminary there were determined optimal balance of the predator and prey.

When studying the biological effectiveness of a simple golden-eyed fly in relation to the cabbage bug, all variants showed a sharp decrease in the number of cabbage bugs, and in the control variant the number of bugs increased threefold (Table 2). As can be seen from the Table 2 experiments with the ratio of predator and prey 1:5, 1:10 on the 8th day of the experience the cabbage bug was completely destroyed.

At a ratio of 1:50, the number of bugs did not decrease. When the ratio of eggs was 1:5, 1:15, 1:25, 1:50 it did not lead to sufficient effectiveness. Full eradication of bugs was observed at a 1:1 ratio, at a ratio of 1:5, a slight decrease in the number of bugs was observed on the 17th day of observation. Thus, the highest efficiencies were observed at a ratio of II-year-old larvae of simple golden-eyed and cabbage bug in a ratio of 1:5 and 1:10. For 4 
day old gold-eyed eggs, this efficiency was observed when the ratio with cabbage bug was $1: 1$ on the 17th day of the experiment.

Table 2. Biological efficiency of a simple golden-eyed fly with different density of cabbage bugs in cabbage seedlings

\begin{tabular}{|c|c|c|c|c|c|c|}
\hline \multirow{3}{*}{ Variants } & \multirow{3}{*}{ predator and prey (ratio) } & \multicolumn{5}{|c|}{ the number of cabbage bugs } \\
\hline & & \multirow{2}{*}{ In experiment } & \multicolumn{4}{|l|}{ days } \\
\hline & & & $5^{\text {th }}$ & $8^{\text {th }}$ & $13^{\text {th }}$ & $17^{\text {th }}$ \\
\hline \multicolumn{7}{|l|}{2017 year } \\
\hline Control & - & $115,0 \pm 0,70$ & $243,0 \pm 1,37$ & $370,0 \pm 0,89$ & $*$ & $*$ \\
\hline \multirow{3}{*}{$1^{\text {th }}$ year old larvae } & $1: 15$ & $45,0 \pm 0,83$ & $28,0 \pm 0,70$ & $3,0 \pm 0,63$ & - & - \\
\hline & $1: 25$ & $189,0 \pm 0,77$ & $94,0 \pm 0,54$ & $75,0 \pm 0,31$ & - & - \\
\hline & $1: 50$ & $130,0 \pm 1,04$ & $109,0 \pm 0,77$ & $35,0 \pm 1,44$ & - & - \\
\hline \multirow{3}{*}{$2^{\text {th }}$ year old larvae } & $1: 15$ & $35,0 \pm 0,58$ & $6,0 \pm 0,67$ & - & - & - \\
\hline & $1: 25$ & $103,0 \pm 0,86$ & $183,0 \pm 0,73$ & - & - & - \\
\hline & $1: 50$ & $183,0 \pm 0,58$ & - & $80,0 \pm 1,37$ & - & - \\
\hline \multirow{3}{*}{4 day eggs } & $1: 15$ & $100,0 \pm 0,54$ & $118,0 \pm 0,70$ & $130,0 \pm 0,94$ & $27,0 \pm 0,70$ & - \\
\hline & $1: 25$ & $125,0 \pm 1,22$ & $125,0 \pm 1,04$ & $70,0 \pm 1,04$ & $70,0 \pm 0,70$ & - \\
\hline & $1: 50$ & $203,0 \pm 0,70$ & $190,0 \pm 1,04$ & $65,0 \pm 0,83$ & - & - \\
\hline \multicolumn{7}{|l|}{2018 year } \\
\hline Control & - & $244,0 \pm 0,70$ & $520,0 \pm 1,04$ & $665,0 \pm 0,70$ & $*$ & $*$ \\
\hline \multirow{4}{*}{$2^{\text {th }}$ year old larvae } & $1: 5$ & $70,0 \pm 0,70$ & $2,5 \pm 0,08$ & - & - & - \\
\hline & $1: 10$ & $136,0 \pm 0,54$ & $12,5 \pm 0,09$ & - & - & - \\
\hline & $1: 25$ & $267,0 \pm 1,14$ & $180,0 \pm 0,70$ & $81,0 \pm 1,30$ & $136,0 \pm 0,83$ & - \\
\hline & $1: 50$ & $430,0 \pm 0,89$ & $310,0 \pm 1,04$ & $360,0 \pm 1,14$ & $432,0 \pm 0,70$ & - \\
\hline \multirow{2}{*}{4 day eggs } & $1: 1$ & $99,0 \pm 0,70$ & $22,0 \pm 0,83$ & $115,0 \pm 1,14$ & $25,0 \pm 1,04$ & - \\
\hline & $1: 15$ & $115,0 \pm 1,14$ & $122,0 \pm 0,70$ & $282,0 \pm 1,04$ & $291,0 \pm 1,30$ & $51,0 \pm 1,44$ \\
\hline
\end{tabular}

Note: * the plant was damaged by cabbage bugs.

\section{Acknowledgments}

We thank the farmer of "Ziroat-21" of the Kushkupir district for practical assistance in doing scientific research on natural entomophages of Brevicoryne brassicae at vegetable fields.

\section{Conflict of interests}

The authors declare that there is no conflict of interests regarding the publication of this paper.

\section{References}

Adashkevich, B. P. (1983). Biological protection of cruciferous vegetable crops from harmful insects (pp. 198-200). Tashkent. Fan.

Adashkevich, B. P., \& Adashkevich, A. P. (1971). Entomophagous of cabbage aphids in the conditions of Moldova and southern Ukraine. Proceedigs of NSRI of PH, 10(2), 76-84.

Adashkevich, B. P., \& Shukuraliev, B. T. (1989). Cabbage pests and their entomophages in Uzbekistan. Biological Method of Controlling Pests of Vegetable Crops Moscow (pp. 106-122). Agroindpublisher.

Akhmedov, M. A. (1977). New species of Syrphidae (Diptera) of Azerbaijan. Biological protection of vegetable crops from harmful organisms. Abstracts of All-Union Conference, 5-7. Kishinev.

Broussol, G., \& Vandel A. (1961). Observation sur la fecondite d’Aphidius brassicae (Hymenoptera) Comptes Rendus, 14, 252.

Claasens, A. J. M. (1995). Observations on the large white, Pieris Brassicae (L.) (Lepidoptera, Pieridae), a butterfly which recently established itself in the western Cape. Metamorphosis, 6(2), 86-93.

Daminova, D. B. (1986). Ecology and significance of predatory syrphids in agrocenoses of Uzbekistan. Cotton Pests and Their Entomophages in Uzbekistan (pp. 85-103). Tashkent. 
Daminova, D. B. (1989). The value of predatory syrphids in reducing the number of cabbage aphids in the conditions of Uzbekistan. Biological Method of Controlling Pests of Vegetable Crops (pp. 122-125). Agroindpublisher.

Fasulati, K. K. (1971). Invertebrate insect field study (p. 424). Moscow: High school.

Hafez, M. (1961). Seasonal fluctuations of population density of the cabbage aphid, Brevicoryne brassicae (L.) in the Netherlands and the role of its parasite, Aphidius (Diaeretiella) rapae (Curtis). Tijdscrift vor Plantenziekten, 67, 445-548.

Hasan, F., \& Ansari, M. S. (2010). Effect of different cole crops on the biological parameters of Pieris brassicae (L.) (Lepidoptera: Pieridae) under laboratory conditions. J Crop Sci Biotechnol., 10, 1007.

Hasan, F., \& Ansari, M. S. (2011). Population growth of Pieris brassicae (L.) (Lepidoptera: Pieridae) on different cole crops under laboratory conditions. Journal of Pest Science, 84, 179-186.

Hwang, S. Y., Liu, C. H., \& Shen, T. C. (2008). Effects of plant nutrient availability and host plant species on the performance of two Pieris butterflies (Lepidoptera: Pieridae). Biochem Syst Ecol, 36, 505-513.

Jackson, J. E. (1997). Vegetable Crop Production in the Communal Areas. In: Mashonaland: Results of a Survey in 1988. In J. E. Jackson, A. D. Turner, \& M. C. Matanda (Eds.), Smallholder Horticulture in Zimbabwe (pp. 3-9). University of Zimbabwe Publication, Harare.

Khamraev et al. (2008). Agroentomological cartogram for the countries of the regions of Central Asia and Transcaucasia (p. 126). Tashkent.

Khamraev, A. Sh. (1995). Entomophage conservation method. Plant protection and quarantine (pp. 17-18). Moscow.

Kopvillem, Kh. G. (1961). Cabbage aphid and cabbage moth, entomophages of these pests in the Moscow region and the possibility of increasing their efficiency: Author's abstract. Academy of Sciences Estonia, 24.

Lal, M. N., \& Ram, B. (2004). Cabbage butterfly, Pieris brassicae L. An upcoming menance for Brassicae oilseed crop in northern India. Cruciferae Newsl, 25, 83-86.

Maslennikova, V. A. (1968). Regulation of seasonal development of parasites. Photoperiodic adaptations in insects and mites (pp. 129-152). Leningrad: LSU Publisher.

Osmolovskiy, G. E. (1964). To the biology of the Apanteles glomeratus L. ichneumon (Hym., Braconidae) cabbage whitefish parasite. Entomological Review (pp. 755-759). Leningrad.

Osmolovskiy, G. E. (1972). Cabbage Pests (pp. 46-58). - L: Kolos.

Pashenko, N. F. (1965). Entomophages of cabbage aphid in south-east of Kazakhstan. Proceedings of Research institute for plant protection. Kazakh Academician of Agricultural Sciences, 9, 113-118. Alma-Ata.

Pimental, D. (1961). Natural control of aphid populations on Cole crops. J. Econ. Ent., 54, 885-888.

Prasad, S. K. (1962). Quantitative estimation of damage to cabbage by cabbage worm, Pieris rapae (Linn.). Indian Journal of Entomology, 23(1), 54-61.

Prasad, S. K. (1963). Quantitative estimation of damage to crucifers caused by cabbageworm, cabbage looper, diatnondback moth and cabbage apid. Indian Journal of Entomology, 23(1), 242-259.

Safaryan, S. E. (1968). Harmful cabbage fauna in Armenia and the biological basis for the development of control measures: Author's abstract Yerevan (pp. 24-28).

Sarfraz, M., Keddie, B. A., \& Dosdall, L. M. (2005). Biological control of the diamondback moth, Plutella xylostella (L.): A review. Biocontr. Sci. Technol., 15, 763-789.

Shapiro, V. A. (1970). The relationship between the cabbage whitefish and its parasite Apanteles glomeratus L. in ontogenesis and the factors that determine resistance to insecticides. RNRI Bulletin, 3-7. Leningrad.

Sibanda, T., Dobson, H. M., Cooper, J. F., Manyangarirwa, W., \& Chiimba, W. (2000). Pest Management Challenges for Smallholder Vegetable Farmers in Zimbabwe. Crop Protection, 19, 807-815.

Sood, \& Bhalla. (1996). Ecological studies on the cabbage white butterfly in the mid-hills of Himachal Pradesh. Journal of Insect Science, 9(2), 122-125.

Stary, P. (1970). Biology of Aphid Parasites with Respect to Integrated Control (p. 656). Dr. W. Junk, The Hague. 
Suitmen, Kh. (1964). Biological method of controlling pests and weeds (p. 575). - M., Kolos.

Talekar, N. S., \& Shelton, A. M. (1993). Biology, ecology and management of the diamondback moth. Annual Review of Entomology, 38, 275-301.

Tursunkhodjaev, T. (1974). Features of the biology of the main pests of vegetable-melon crops and their entomophages in conditions of East Fergana: Author's abstract (p. 20). - Tashkent.

Yarkulov, F. Ya. (1997). Entomophages of leaf-eating pests of agricultural crops in Primorsky Krai. Plant Protection and Quarantine, (11), 26.

Younas, M., Naeem, M., Raquib, A., \& Masud, S. (2004). Population dynamics of Pieris brassicaeon five cultivar of cauliflower at Peshawar. Asian J Plant Sci, 3, 391-393.

\section{Copyrights}

Copyright for this article is retained by the author(s), with first publication rights granted to the journal.

This is an open-access article distributed under the terms and conditions of the Creative Commons Attribution license (http://creativecommons.org/licenses/by/4.0/). 